\title{
COULD WE CADASTER FASTER IN AN INTEGRATED IT SYSTEM BY USING UAVS WITH GIS SERVICES IN A CLOUD INFRASTRUCTURE?
}

\author{
Mihnea Mihailescu*, Diana Irimia**, \\ Răzvan Rădulescu ${ }^{* * *} \&$ Răzvan Simion ${ }^{* * * *}$
}

There is a significant number of geographies around the world where the percentage of land with cadaster and land books registered in an integrated IT system is rather low and increasing it is a real challenge for all stakeholders: the governmental institution managing the domain, surveyors, IT businesses and citizens. The typical duration and costs are too high for collecting all geospatial and deeds data, for all processing phases necessary before registering all data in a centralized IT system and issuance of land books. In order to improve the duration and costs of mass registration we analyze the involvement of modern technologies along the process, automation of eligible registration sub-processes, usage of UAVs for faster field data collection and storing and sharing all work in progress in the cloud infrastructure. We measure the improvements for each subprocess, analyze the impact of proposed actions, tools and environments, and quantify the duration, costs, quality and total cost of ownership for each scenario, based on simulations and prototype construction, to determine whether such improvements are a real "win" for all stakeholders. Comparing the mass registration process in several scenarios with different levels of automation on the sub-processes reveals a decrease of the duration or cost of sub-processes with 20-40\%, a decrease in number of validation iterations with $25-50 \%$ and the improvement of public registration service transparency for the citizens. We argue that when such a technological improvements are applied to a large scale registration, the total cost of ownership of the IT system could be amortized early in the regstration process with a clear impact on the economy and public service quality of the registered geography.

INTRODUCTION......................................................................... 378

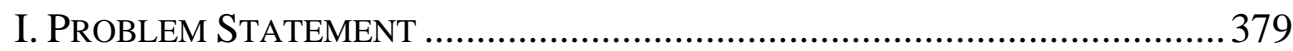

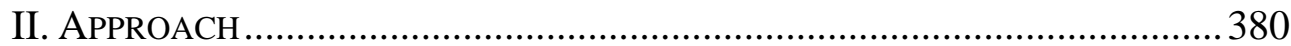

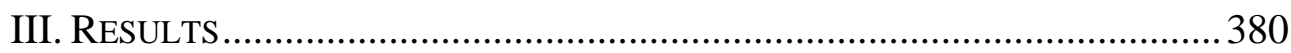

A. Assignment Preparation (Start-Up).................................. 380

B. Data Collection and Processing .......................................... 384

\footnotetext{
* Mihnea Mihailescu, Consultant in land management IT services sector. Email: mihnea.mihailescu@gmail.com.

** Diana Irimia, Business Analyst in land management IT services sector.

*** Răzvan Rădulescu, Subject Matter Expert in land management IT services sector.

**** Răzvan Simion, Solution Architect in land management IT services sector.
} 


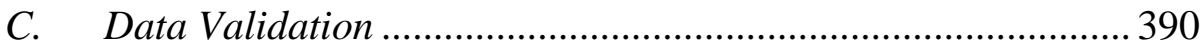

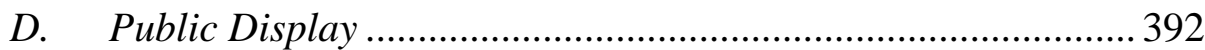

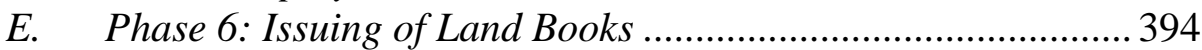

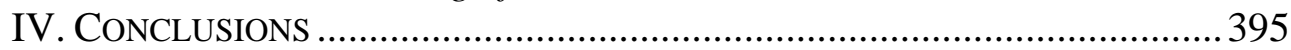

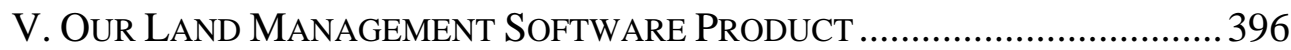

VI. LAND ADMINISTRATION IMPACT ON THE GOVERNMENTAL ECOSYSTEM

.398

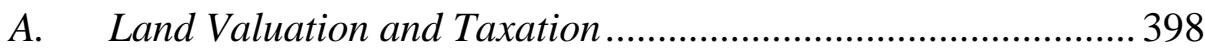

B. Emergency Management ...................................................... 400

\section{INTRODUCTION}

Over the history, land has proved to be one of the most important resources that played a major role in the evolution of our species, as it offered the ingredients the human kind needed to survive and develop: food, construction materials, minerals etc. Due to these, it still represents an endless source of disputes of diverse magnitudes and impacts.

Tribes, communities, societies have developed faster as they found more efficient ways to manage land. From finding better tools and techniques to work land in order to produce food, the concept of land management has continuously evolved; nowadays more efficient politics in poverty reduction, sustainable urbanization, climate change government, equity assurance represent the current challenges. However, due to unequal development of communities around the world, all types of needs, from basic to sophisticated, are present on the public agendas of local administrations, governments, international institutions.

Land registration is the process of official identification and recording of the property boundaries, rights, restrictions and responsibilities through deeds or title. It is regularly conducted by central or local public authorities. Land registration represents the main pillar of land administration as it is commonly accepted that is difficult to manage the "unknown".

All around the world, governments are looking into implementing or continuously optimizing and adapting their land registration systems, as economic and social needs are rapidly changing. As many developing countries are dealing with budgetary restrictions, the need of self-sustainable solutions is a constant challenge.

In many countries, individual, on-the-need basis land registration represents the initial and still most used process. It responds to the urgent needs of the parties that can afford to pay its price. Even if the government facilitates the individual registration by offering fee and/or tax discounts, it 
will take an indefinite time to complete the registration and to obtain fair quality data (ex. gaps and overlaps may probably occur).

Mass or systematic registration is the alternative to individual registration process. It is usually run or supervised within programs by local or central public authorities who can afford to support the cost, to manage the complexity, to offer the legal, procedural and technical frameworks that proved to be compulsory ingredients to success.

The design and preparation stage of these programs is probably the most important time to address the potential systemic problems as legal framework ambiguities, poor data quality of property documents (e.x. titles), incomplete project procedures and insufficient training material and courses. Experience has shown that ill prepared programs not only fail but they use up the goodwill and enthusiasm that are essential for the success of a mass campaign, such as systematic registration. ${ }^{1}$

\section{PROBLEM STATEMENT}

Mass registration process is probably the most efficient way to obtain a complete cadastral map and property rights (restrictions, responsibilities) registry for certain geography, in a time frame that is considered acceptable in the current world landscape.

The process complexity can be evaluated as high considering its following characteristics:

- diverse types of stakeholders (citizen, companies, surveyors, public authorities) in terms of culture, communication habits, institutional relations, knowledge and understanding of laws and procedures;

- massive data management of various type, quality, availability;

- extremely important results for the further development of the socioeconomic environment.

IT companies and domain experts are striving to find ways to connect the technological boom of the last decades with the development of systematic registration by finding the appropriate IT solutions to key business problems.

The target of our study is to explore ways of optimizing this process from a technology-based perspective, by assessing the impact of the proposed solutions to the quality and total cost of ownership, to determine whether such improvements are a real "win" for all stakeholders.

\footnotetext{
${ }^{1}$ Systematic Property Registration: Risks and Remedies (2016), https://openknowledge.worldbank.org/handle/10986/26048.
} 


\section{APPROACH}

Our methodology is to study each phase of systematic registration process in order to identify activities that can be supported by an IT solution, to validate their effectiveness through the analysis of the results of the projects that used such or similar solutions or simulated scenarios.

The most common phases of the mass registration process are:

- assignment preparation;

- data collection and processing;

- data validation;

- public display and complaint management;

- issuing of registration certificate.

We have identified these phases based our experience and analysis of the available mass registration methodology.

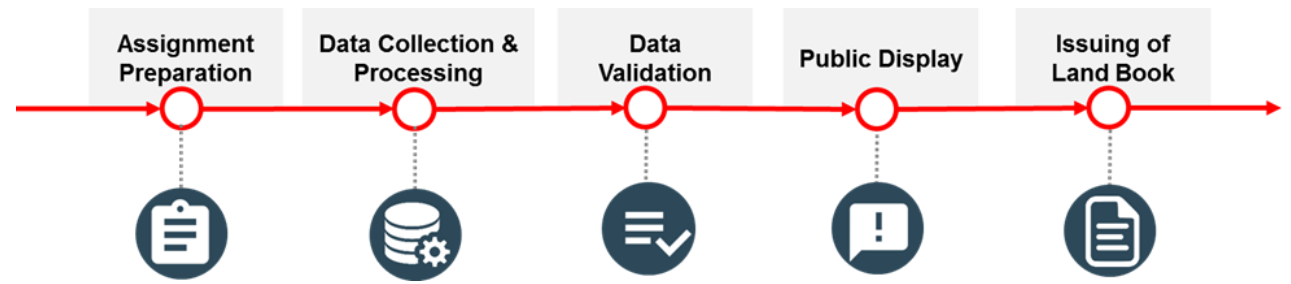

Figure 1 Phases of a standard mass registration process.

The following chapter presents the analysis of each phase activities and the solutions we have identified to improve the duration, effort or cost.

\section{RESULTS}

\section{A. Assignment Preparation (Start-Up)}

This is the initiation phase when the communication, procedural, technical infrastructure of the project are setup.

\section{Communication Infrastructure Setup}

An efficient mass land registration process requires a good collaboration between all involved parties that can be achieved using effective information dissemination tools and methods to inform the stakeholders about their requested involvement and benefits, the procedures they have to comply with, to facilitate their communication, to push alerts and reminders in order to avoid side slips.

In our opinion all of these can be enabled by an efficient 
communication platform based on modern technology - a Project Portal. The uploaded content may address:

- project plan: activities, milestones, owners;

- simplified version of procedures, grouped by activity and/or role incharge;

- dashboards with the evolution of main project indicators (ex. surveyed parcels, interviewed persons);

- events which trigger alerts/reminders: milestone approaching, delays in delivery, rejection of critical areas during validation phases which requires immediate corrections etc;

- templates of documents;

- contact information of involved institution representatives.

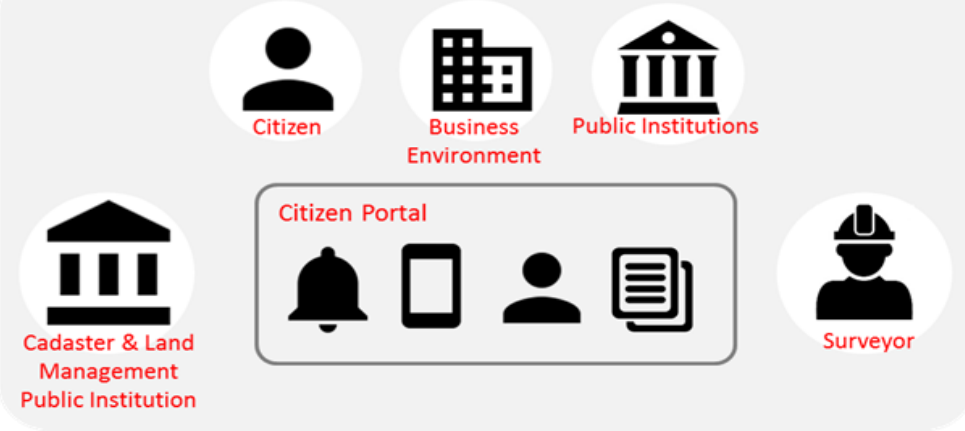

Figure 2 Citizen Portal.

The solution implementation analysis should consider some key attributes of the audience such as: cultural patterns, computer literacy level and internet penetration rate as the success of adaption is highly dependent on these. The result of this analysis should determine the adequate level of formalization, access and communication methods to be used (ex. sms, email) in order to maximize the capabilities of this tool.

In conclusion, the implementation of this modern communication tool may represent an improvement to the general process if the target audience possesses the required minimum technical and educational level. In that case, we consider it may be a reliable and efficient communication channel and a good alternative to the traditional one which is based on direct human interaction, information exchanged on paper, centralized and controlled by local (administrative) authorities.

\section{Data Infrastructure Setup}

The mass registration process is characterized by intensive data 
management activities: collection, aggregation analysis, processing, displaying operations are (sometimes) repeatedly performed. Impressive volumes of scatter, incomplete, various types of data represent inputs that generate high processing whenever they are manually, redundantly, insecurely handled. Additional costs may occur if information is exchanged on paper: material, transportation, cover of eventual losses.

\section{Legacy Data}

Essential data is usually hosted and managed by different public authorities. Cadastral maps, enviromental plans, taxation zoning, urbanization plans etc. should be centralized, cleansed, analysed and spatially indexed in order to serve the project scope. Similar approach should be followed with respect to alfanumeric data registries: titles, taxation units etc.

For legacy data which rests on paper, a cost-benefit analysis may conclude that the digitalization of the legacy registry certificates (land books, land cards), property documents and map archives should be run to speed up the data collection phase activities.

The duration of such projects depends on factors like the quality of the scanned paper, the overall performance of the equipment, the organization of the scanning activity (workflow), the experience of the human operator, the involement of the beneficiary in the preparation phase etc.

Our case study is the digitization process of land books. A number of 80,000 land books with an average number of 9 pages were scanned with a speed of 2,800 pages per hour in less than 2 months. The resulted digital archive was used in the mass registration process managed by the local administration (City Hall).

In our opinion, it is important that legacy data are checked for inconsistencies and the major findings are fixed before sharing it with the involved parties. A special attention should be paid to "property-proof" documents like titles in case they represent the baseline for mass registration process. They should be digitized, their main attributes value should be stored into a database and cleansed using consistency check algorithms and correlations with other property-related data repositories, such as taxation database.

Based on our expericence on the analysis of over 10,000 parcels we can say that around $15 \%$ of the corresponding property titles contain data completion (typos) or corellation (totals) errors. The manual validation of the title main attribute value (cadastral identifier, parcel area) for each parcel 
may take up to 10-15 minutes per parcel which leads to 200-300 working days. We estimate that reducing the error occurences in title-related data with $25 \%$ may improve the data collection activity that consists of spatialproperty title data paring with $20-30 \%$ in terms of effort.

Our proposed solution for managing legacy data is an IT platform which has the appropriate tools to:

- import and remotely access external data exposed in standard formats (services);

- consolidate and index data of different types on regular basis;

- facilitate data cleasing by data correlation tools;

- offer data interrogation via internal user interfaces or services.

The core components of the solution are represented by:

- an alphanumeric engine that features full-text search, hit highlighting, faceted search, real-time indexing, dynamic clustering and rich document handling;

- an spatial engine that runs advanced queries on internal and external sources exposed in standard formats, can manage huge data caches, may generate analytical reports based on real-time identified spatial data relations.

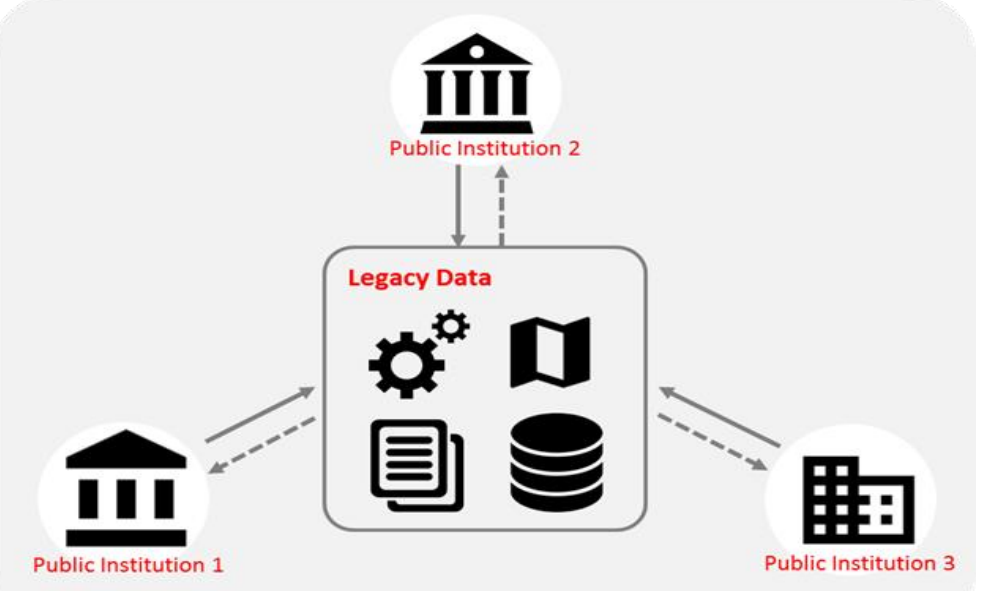

Figure 3 Legacy Data Platform.

The data managed by the platform should be organized around the two main pillars of land registration: the property and the parties which hold rights, responsibilities or which are restricted to perform actions in relation to a specific property. The main goal of the data platorm is to provide consolidated, fairly realiable, easy accessible, baseline data for supporting the project publicity and field visits. 


\section{B. Data Collection and Processing}

This phase is characterized by extensive field activities conducted by a team (private surveyor company, public cadastre institution) which is responsible for interviewing, surveying and collecting ownership-related documents from citizens and companies.

\section{Cadastral Mapping}

The cadastral mapping activity is currently benefiting a lot from the huge development of the "unmanned aerial vehicles (UAVs), commonly known as drones. These commercial drones are small and feather-light. They offer a turnaround mapping service from planning to product in a matter of days or weeks rather than months or a year and at a fraction of the cost of conventional aerial surveying using manned aircraft" 2 .

These advances were possible due to the rapid development of specialized software algorithmes that enabled the tessellation of aerophotograms taken by non-metric cameras with very good results in terms of precision.

Our case study to prove that "this new approach significantly reduces the cost and time for high quality cadastral mapping" ${ }^{3}$ is based on the following figures.

Table 1 Technical Parameters.

\begin{tabular}{ll}
\hline UAV & HIRRUS $^{4}$ \\
\hline Cruise speed & $90 \mathrm{~km} / \mathrm{h}$ \\
Wigspan & $3.3 \mathrm{~m}$ \\
Range & $15 \mathrm{~km}$ \\
Altitude (max) & $3,000 \mathrm{~m}$ \\
Autonomy & $3 \mathrm{~h}$ \\
Get-off system & Launching platform \\
Landing system & Air-drop \\
Load (max) & $0.9 \mathrm{~kg}$ \\
Camera & Sony Nex 7 (https://en.wikipedia.org/wiki/Sony_NEX-7) \\
\hline
\end{tabular}

\footnotetext{
${ }^{2}$ World BANK GRoup, Drones OfFer InNOVATIVE SOlution FOR LoCAL MAPPING (Washington DC 2016), http://www.worldbank.org/en/news/feature/2016/01/07/drones-offer-innovative-solution-forlocal-mapping.

${ }^{3}$ World Bank Group, Drones OfFer InNOvative Solution For Local MAPPING (Washington DC 2016), http://www.worldbank.org/en/news/feature/2016/01/07/drones-offer-innovative-solution-forlocal-mapping.

${ }^{4}$ HIRRUS is a trademark of a research project between Autonomous Flight Technologies, www.aft.ro and Teamnet International, www.teamnet.ro.
} 
Table 2 Flying Plan, Data Collection and Processing Parameters.

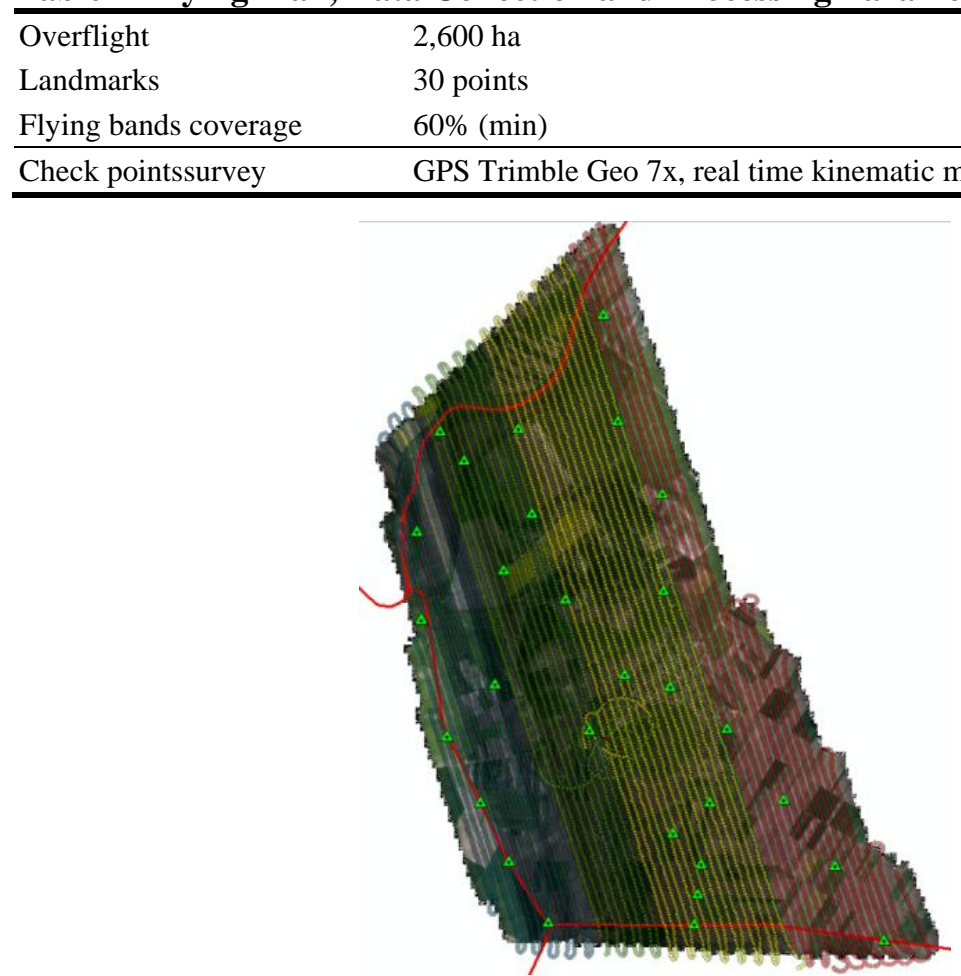

Figure 4 Flying plan.

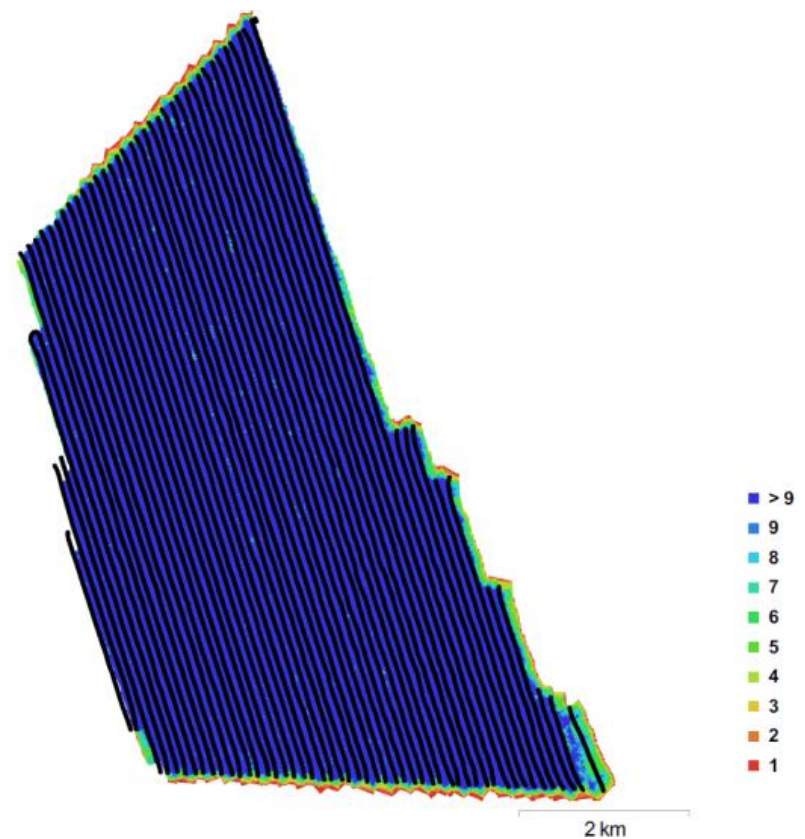

Figure 5 Photogram coverage. 


\section{Data Processing}

A number of 10,000 images have been processed going through these steps: automatic alignment of images (tie points generation), scene reconstruction, placing of measured markers, scene optimization, full 3D model reconstruction (dense points cloud generation), digital surface model generation based on 3D model, images ortho rectification, mosaicking of rectified images and the export of products (ortho images and digital surface model).

(1) Results

The resulted products consist in an orthophoto plan of $5 \mathrm{~cm}$ GSD resolution and a Digital Surface Model of $20 \mathrm{~cm}$ GSD resolution.

Table 3 The Orthophoto Accuracy Parameters (Meters).

\begin{tabular}{|l|l|}
\hline Root-mean-square deviation & $0.045 \mathrm{~m}$ \\
\hline Average deviation & $0.036 \mathrm{~m}$ \\
\hline CE90(CMAS $)=$ & $0.068 \mathrm{~m}$ \\
\hline CE90(Empiric) $=$ & $0.071 \mathrm{~m}$ \\
\hline CE95(CMAS $)=$ & $0.078 \mathrm{~m}$ \\
\hline
\end{tabular}

Here are some samples:

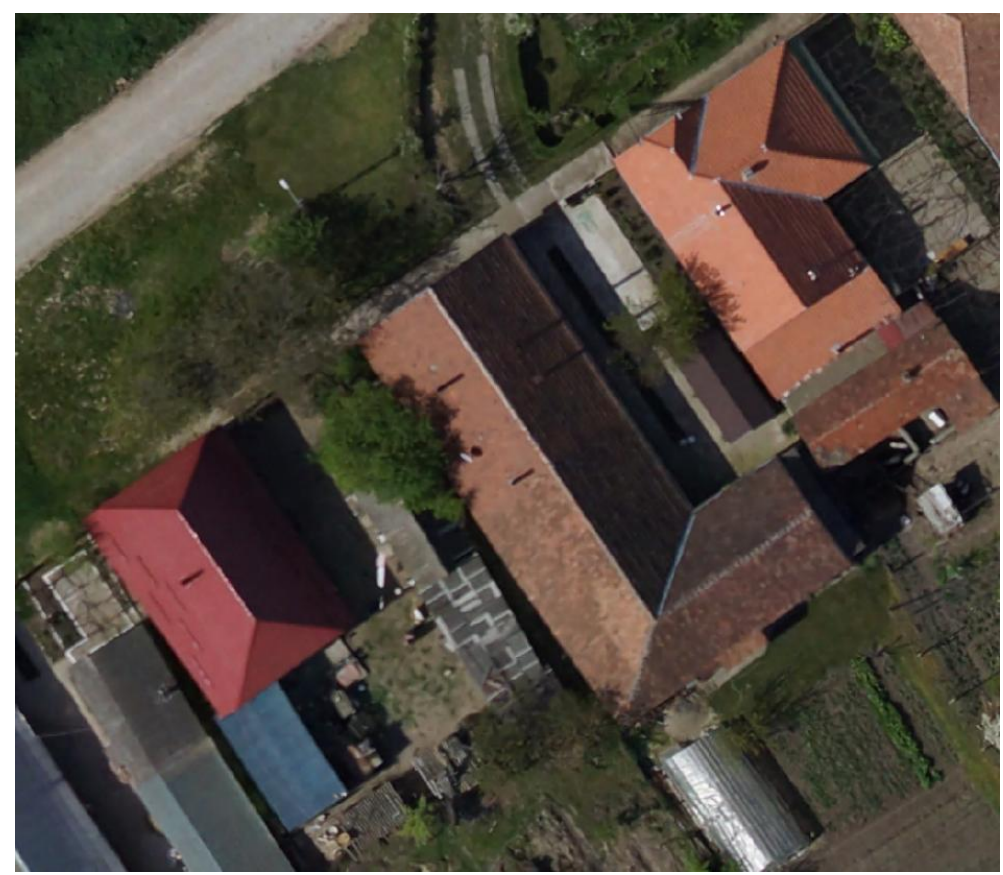

Figure 6 Orthophoto Map $($ GDS $=5 \mathrm{~cm})$. 

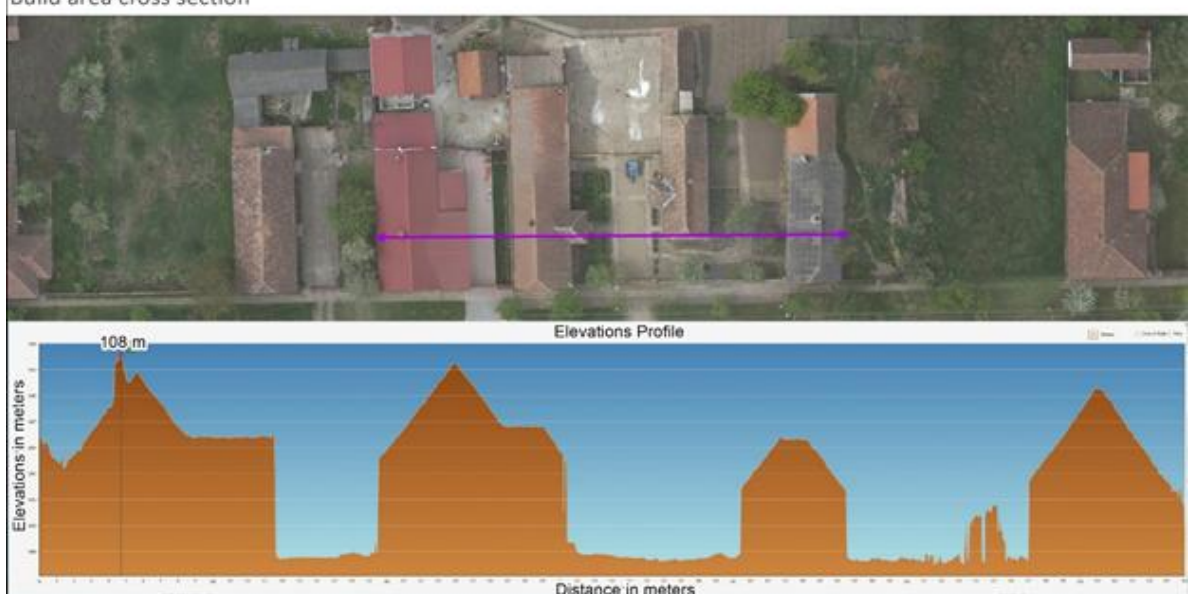

Figure 7 Digital Surface Model (GDS $20 \mathrm{~cm})$.

We have measured the vectorizing effort of around 0.5-1 hour per land parcel, including the field validation work which is absolutely necessary for boundaries which cannot be drawn from the office due to visual obstacles (ex. vegetation, clouds) etc.

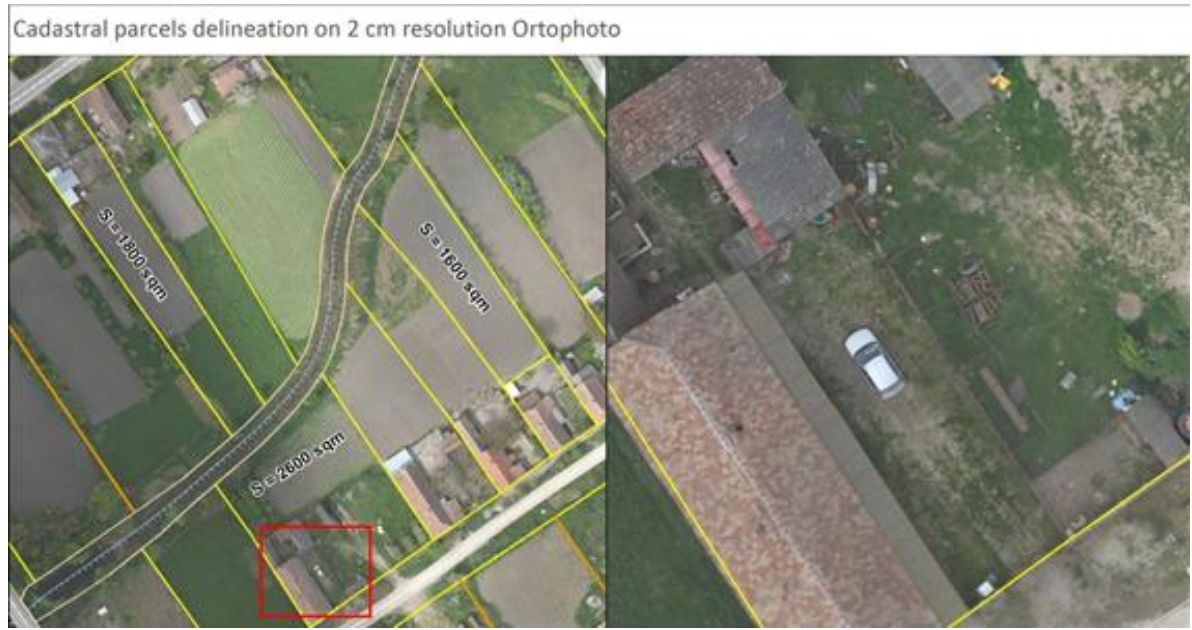

Figure 8 Cadastral Map.

(2) Conclusion

The precision of the ortho photo map recommends the use of the products derived from UAV-collected aerial images for a variety of areas in particular the systematic registration of lands, urban, infrastructure and utilities planning, land use monitoring etc. It will reduce time and lower costs at a reasonable quality of the final product. 


\section{Field Visit Management}

The activities of this resource consuming phase can be optimized by facilitating the organization, capturing and exchange of data between the ground-based and office-based teams.

Below are briefly presented some improvements which can speed up the process by using a dedicated (mobile) application connected to a central server:

- team structure and the optimized routes of the areas to be visited can be defined beforehand, using specialized features;

- team members may access online or check-out for offline use essential spatial and alphanumeric data for the allocated visit areas;

- list of persons and immovables with a selected list of atributes;

- customized interview forms, prefilled with identification data for parcels, parties and legacy property documents;

- the parcelor the address of the person to be interviewed can be located using GPS technology depending on availability;

- the interview results can be directly input into the mobile application along with the photocopy of the ownership-related documents;

- the field-collected spatial vector data can be rapidly transferred to the central system by interconnecting the total stations with the mobile application.

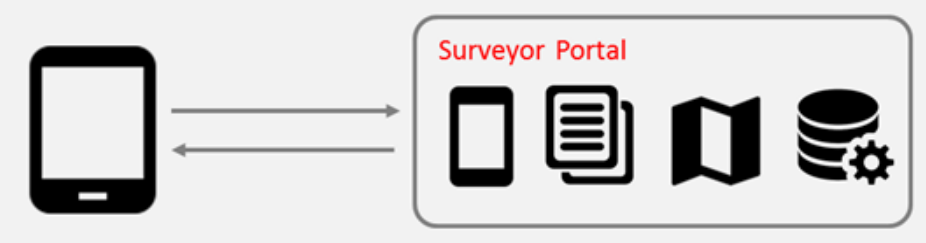

Figure 9 "Field Assistant” Mobile Application.

Our study, based on interviews with surveyor team leaders, show the following improvements in the scenario of using the above mentioned features:

- the effort related to team allocation activity will decrease by $50-60 \%$;

- the preparation of the interview (per land parcel) will be reduced by $30-50 \%$ from 30 to 15 minutes;

- the filling of interview form and property documentation photocopying duration (per land parcel) will decrease by 50-75\% from 20 minutes to 5-10 minutes; 
- the collected data transfer per cadastral zoning (cadastral sector) will decrese by $33-50 \%$ from 3 days to less then 2 days, considering the paperbased information cannot be excluded from this activity.

The above figures are highly dependent on the methodology required by the project, the experience of the team members and performance and availability of internet connection etc.

\section{Data Processing}

This activity is dedicated to the management of collected data (spatial, alphanumeric and fotocopies): consolidation, processing, validation, correction, transformation and export. All these operations are successively and repeatedly applied in order to meet the quality standards required by the beneficiary authority.

Our proposed solution is a set of capabilities provided by an IT application to assist the surveyor in the manipulation and validation of the collected data. It can be seamlessly integrated with the application we have proposed for data collection to ensure a smooth data feed from collection to processing operations.

This application may offer the following set of features:

- import of various spatial data file formats;

- enhanced data entry capabilites for capturing alphanumeric property description and right-related data;

- import of standard format documents (pdf): field interview sheets, property documents, building unit blueprints;

- advanced querying focused on modern text search capabilities;

- integration of external spatial data sources (standard file and service formats) and real-time spatial interrogation;

- manual and automated triggered validations based on a configurable business rule engine for both spatial and alphanumeric data;

- quantitative and qualitative data evaluation reports;

- generation of specialized reports like: cadastral plan, land parcel and building index, owners' index;

- export of spatial data and associated right registrations in an XML format transport file (standards may be used: i.e. GML). 


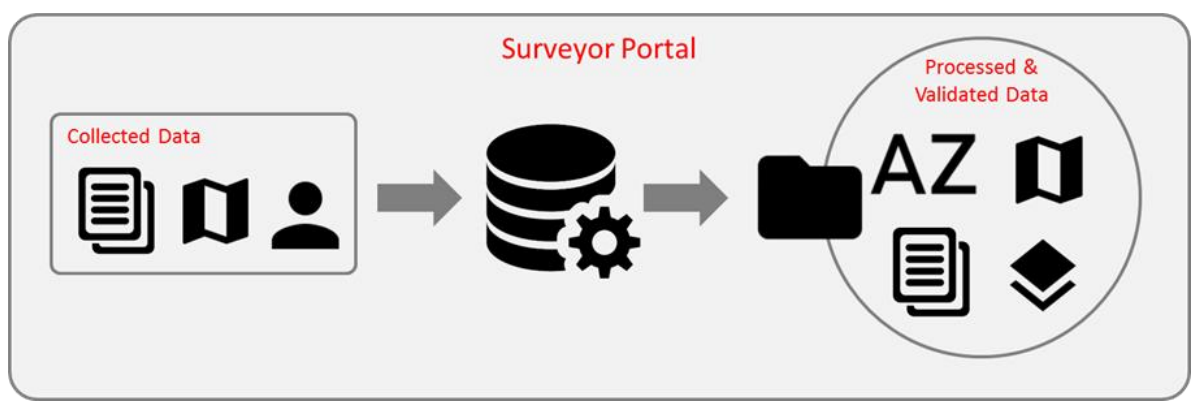

Figure 10 Data Processing.

The surveyor team leaders we have interviewed during this case study emphasized that this bundle of features will reduce the data processing effort by $20-30 \%$. They consider the business rule engine, evaluation reports and XML transport file generator to be tools which will improve most their data processing and packaging activity.

\section{Services from Cloud}

The implementation and further administration of the proposed IT solutions for field data collection and processing may engage a total cost of ownership which cannot be profitably absorbed by small and medium surveying companies.

A more increasingly adopted solution is to access such IT capabilities as software services provided via an SaaS software distribution model in which the provider makes available its application capabilities via an internet platform that serves as a host. This contracting approach lowers the capital expeditures of the service beneficiary and ensures a flexible business relation with the provider. High availability, strong performance and security are becoming standard characteristics of SaaS.

In conclusion, this contracting model should be an alternative not to be missed in the planning of IT capabilities acquisition or distribution.

\section{Data Validation}

The activities of this phase are targeted to validate the high volumes of the collected data against the content of the corresponding ownershiprelated documents and a set of pre-defined business rules which address the structure, correlation and completeness.

As systematic registration deals with volumes of cadastral unit (parcel, immovable etc.) data which belong to the same superior zoning, mass validations are required at least for topological reasons. The huge amount of 
data needs to be verified in a rather short period of time as it is presumed it may change in real life due to nature, owner's or authority's will.

Our proposed solution to improve the activities of this phase consists inan information system which features capabilities for:

\section{Data Exchange}

The transfer of the collected data can be done using:

(a) Edicated user interface which offers to surveyor operators all necessary features to directly input and real-time validate data into the beneficiary system;

(b) transport file format for spatial data, alphanumeric data or both, based on standard international formats (i.e. GML);

(c) specialized service interface which enables secure and quality controlled data transfer between surveyor and beneficiary systems.

The last two options may be preffered by large surveying companies which possess the requested technical capabilities to (directly) connect their system to benecifiary system, whereas the small ones and individual surveyors may follow the first two options which requireless expertise in IT solution and lower costs.

\section{Data Validation}

It is better to start the validation as soon as possible along the process in order to provide feedback which can be faster incorporated into the deliverables. Considering this, the information system should integrate data validation in data transfer methods: data entry forms (client side), technical specification of transportation file format (xsd) and web services (serverside) and it should offer easy-to-access result validation reports and alerts.

As soon as data is transferred, the electronic validation operations may be manually or automatically triggered based on the rules managed though a business rule engine:

- alphanumeric data is scanned to detect any deviations;

- topological relations are checked using spatial features.

Both provider and beneficiary users can be authorized to perform data transfer (where applicable) and validation activities within the platform, so that data updates are performed faster and real-time official feedback is accessible be all parties involved. This will reduce the overall number of data production/correction - transfer validation iterations which will consequently shorten the duration of data validation phase.

The system can offer sampling mechanisms to select the data which 
has to be visually checked against the content of the field-collected or other legacy documents. This approach will increase trust and lower the possibility of the validation operators to commit abuses by applying the same rules to all cases.

The validation decisions (approval, rejection) and progress (how many) should be transparently shared to all involved parties in order to rapidly find solutions and to apply corrections. Communication platform may be used to triggeralerts and to push reminders. Cadastral map, built-in and custom reports should be available to disseminate relevant information.

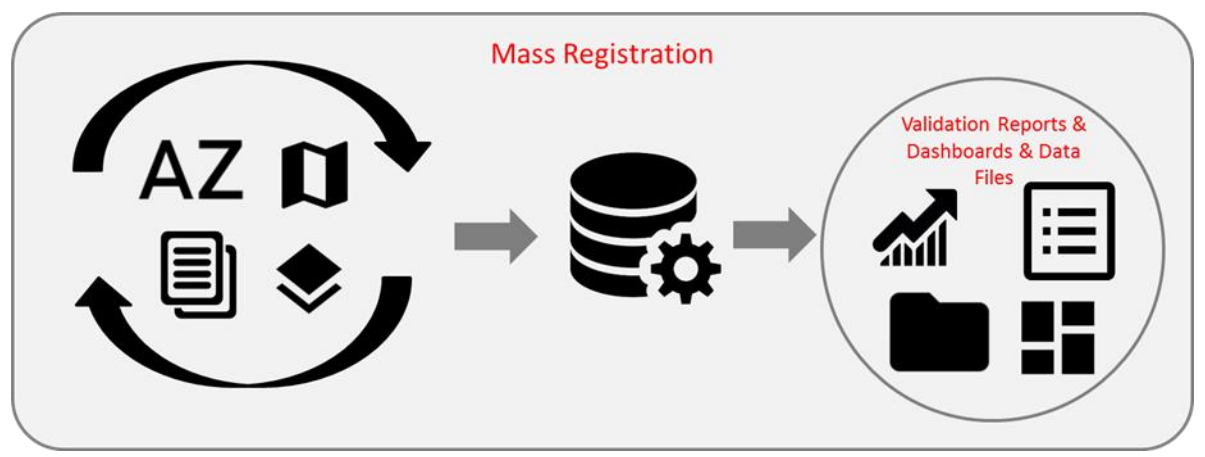

Figure 11 Data Validation.

The results of the question naire-based study show that a transparent validation process, based on an IT platform which interconnects data providers (surveyors) and beneficiaries (land registration office specialists) and provides a common tool set for data exploration and validation is highly appreciated by the involed parties. The main arguments are:

- A fair treatment as the validation tools and result reports are accessible to each side;

- The standardization of the validation procedure by continuous integration of the solutions to the exceptional cases;

- The reduction of thecorection-validation iterations with 2-4 weeks per delivery (cadastral sector) as the surveyor can initiate the correction operations as soon as the rejection motivation is registered.

\section{Public Display}

The traditional public display procedure based on printed cadastral plans, property and owner oriented indexes, called cadastral technical documents, which are usually pinned on boards located at City Halls or Cadastre/Land Registry Offices will continue to be primarly used as it is the only format of presentation that's accessible to large masses of people. 
In regions where internet penetration has a good rate, the public display can be supplementary realized in a digital environment.

Our improvement proposal is an IT system component which provides the following features:

- Cadastral technical documentation rendering in printable format;

- Automated websites generation to present cadastral map, associated property rights, restrictions and responsibilities (if registered) and the copies of the collected documents (where available);

- Dedicated online forms for capturing user disputes in relation with property boundaries, attributes and right registrations and to upload relevant documents;

- Automatic generated messages to inform about the dispute solutioning progress;

- User registration and authorization workflow.

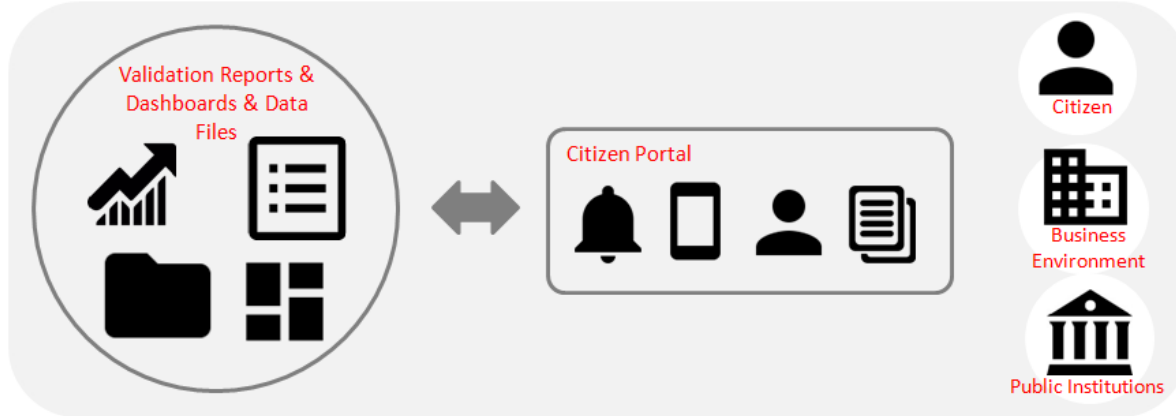

Figure 12 Public Display.

The feature which offers to the project leading authority the possibilty to generate the final version of the cadastral map and property registries at the end of the validation phase is considered a major process improvement by the surveyor team leaders we have questioned. This way, the validated data set is the only, secure, official source for the printed systematic registration documents which are displayed on the local authority boards and the website which facilitates the remote interaction with the owners who cannot be present onsitefrom various reasons (distance, illness etc.) to visually check the displayed information. They estimate this feature may determine a decrease with $30-50 \%$ of the effort associated with the management of these documents (intermmediate incorporation of fixes and deliveries).

Online registration and real-time information of the disputes facilitates the early start of the investigation and correction activities and ensure a transparent and collaborative environment for the entities which have to address the reported issues. From our respondents point of view, this is so 
important as the major data inconsistencies, usually related to the mapping discrepancies between the field reality and property documents, are addressed within this phase.

\section{E. Phase 6: Issuing of Land Books}

At the end of the display phase, the public validated data which incorporates the disputes' resolution is uploaded into the land management system (Cadaster Registry, Land Registry) and the document which represents the evidence of registration is issued.

The data specification used within mass registration process should be compatible with the one implemented by land registration management system in order to ensure a smoother transfer of data.

It is vital that the cadastral/land registry authority has an electronic land registration system so that the results of the mass registration project will be further dinamically updated to reflect the changes which occur in real life related to property boudaries (natural alterations: floods, river course changes, landslides) and rights (transfer of property rights etc.).

The registration certificate (land book, land card, excerpt etc.) is usually issued within the land book registration system as it provides such built-in functionality by default.

Our proposal in terms of improvement is an integrated solution which:

- Connects systematic registration solution with the core land registration management system; PDFs);

- Offers mass registration certificates generation capabilities (merged

- Integrates with external systems (i.e. Citizen Portal) via web services to facilitate automatic or self-service distribution of e-signed electronic version of registration certificates.

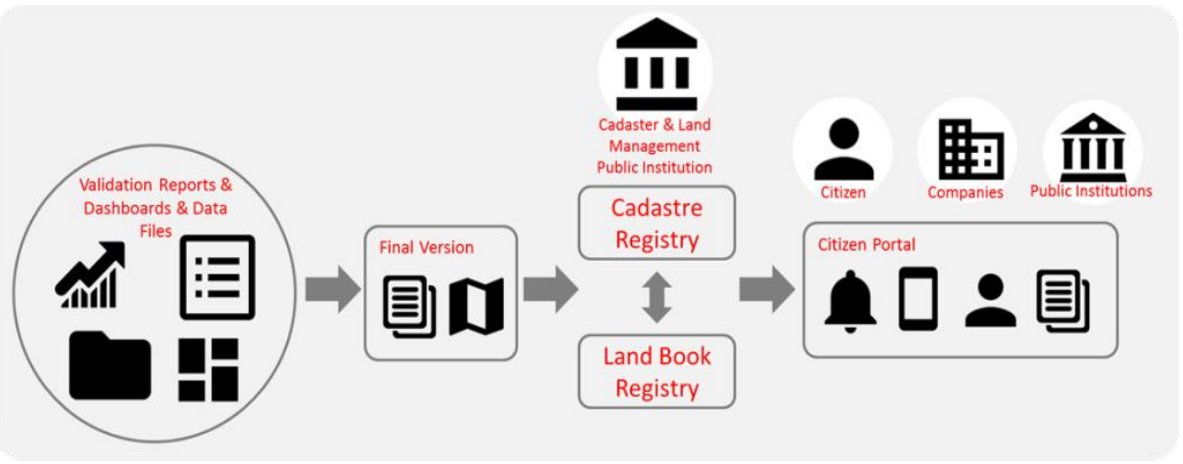

Figure 13 Mass Registration Process Finalization. 
The practical adoption of the mass document generation and printing of the registration certificates (cadastral plan excerpt, land book excerpt) will reduce the average duration of obtaining the printed copy to seconds per certificate (average no. of pages/document: 2 ).

A server signed e-version of these documents can be downloaded by citizens and official representatives of the companies as long as they have an authorized account and are registered as owners or other property right holders. They can make use of this electronic copy as long as the required legal framework is enforced, therefore the potential recipients officially recognize its legal value.

\section{CONCLUSIONS}

Nowadays, the systematic registration process can be more efficiently addressed by integrating modern data collection technologies, software capabilities, specific knowledge within the process. A detailed analysis of each phase is compulsory to understand the specific needs, select the right IT solutions and adapt them to match the requirements, integrate and tune the entire system in order to maximize the results of its support in day to day business outcome.

The solutions we have presented for each phase generate the highest added value when they are integrated to act together as a system. The image below offers the big picture: stakeholders, components and data flows.

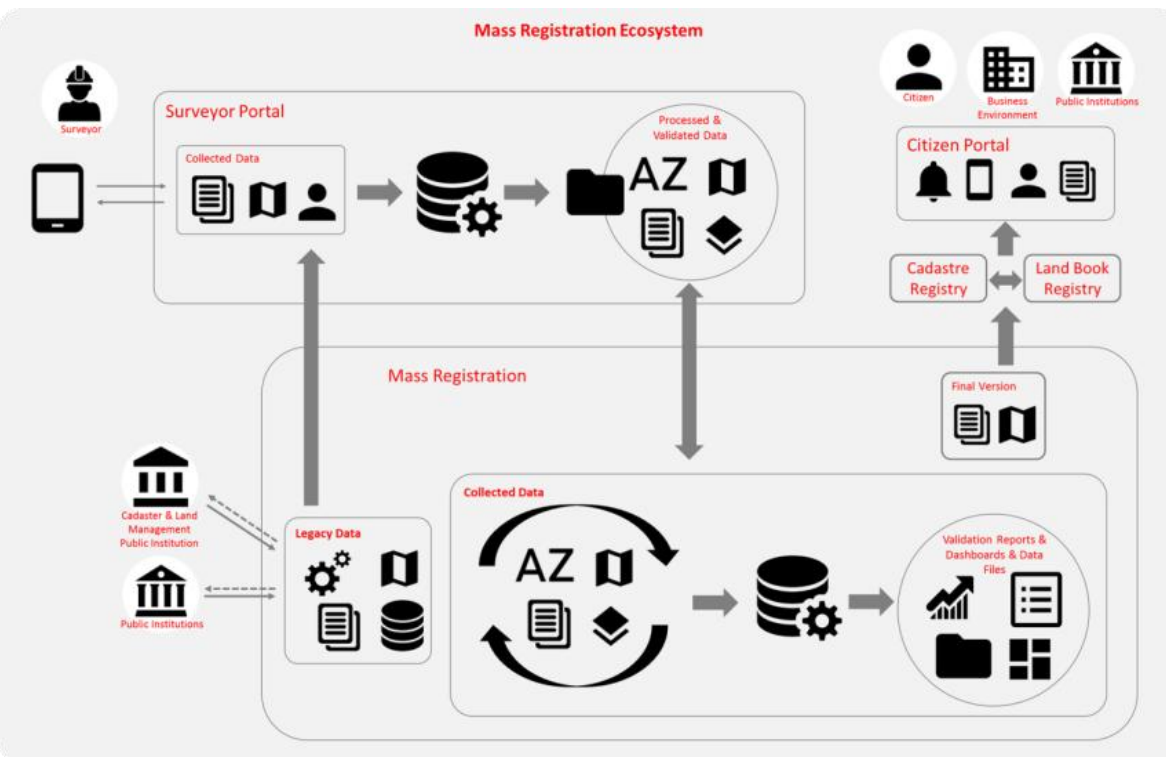

Figure 14 Mass Registration Ecosystem. 
The adoption of such a system is a complex, iterative process itself that may require piloting phases followed by the deployment of the components which may add the highest value to current landscape.

Our estimations show that an average improvement of duration or effort with $20-40 \%$ is achievable. Its scale differs from phase to phase and it is dependent to the level of automatization. The implementation of real-time access to data validation decisions and citizen complaints may reduce the number of validation iterations with $25-50 \%$.

Communication and collaboration tools are essential components in the current social environment as the need of information is continuously increasing driven by the technological boom. A smoother and more transparent access to information related to the property registration process will trigger an increase of population trust, involvement and general satisfaction.

We would like to take this opportunity to introduce our Cadaster and Land Management technology expertise. We are a top IT company in Romania, with presence in Europe, Middle East and Africa. We provide complex IT systems' integration projects and proven product suites in areas of Land Management, Healthcare and Smart Cities, with more than 100 years of cumulated cadaster and land management IT services experience in our team.

\section{OUR LAND MANAgEMEnt SOFTware Product}

Our Cadastral Software Product is a suite of Integrated Land Management Applications which provides complete services for the management of cadastral and land book information. The solution automates all cadastral and land registry data updates and legal outputs.

Main benefits for the regional/central government:

- Creates a system which can process more citizen requests, faster, thus increasing the state budget revenues;

- Reduces time required for delivering business outputs (i.e.: excerpts can be delivered instantly, online, fully-automated);

- Integrates legacy systems through seamless modular architecture replicability;

- It is built on most reliable technologies provided by solid vendors like Oracle, Microsoft, ESRI and IBM, or in an open-source architecture;

- It is compliant with the international standards requests: OGC (Open Geo Consortium) and LADM (Land Administration Domain Model). 


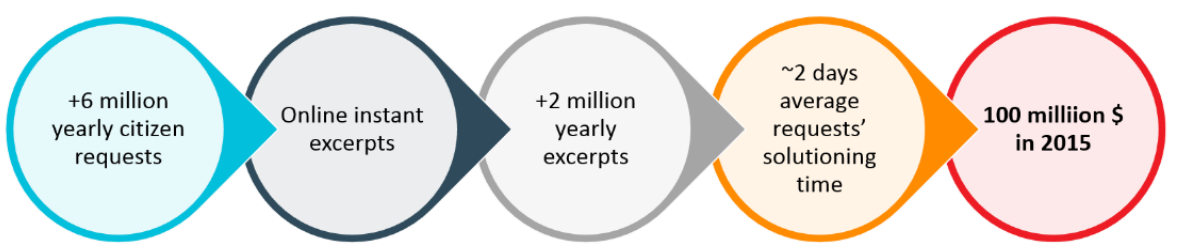

Figure 152015 Results of One System Implemented by Our Team.

The Cadastral Software Product brings openness, interoperability, standardization, automation and flexibility.

The list of main components for our product includes: Registration, Land Book Registry, Mass Registration, Cadaster Registry, Citizen Portal, Surveyors Portal, Spatial Data Integration, Notification Engine, Administration Audit \& Monitoring and Business Intelligence \& Reporting (and a complete list is shown in the picture below).

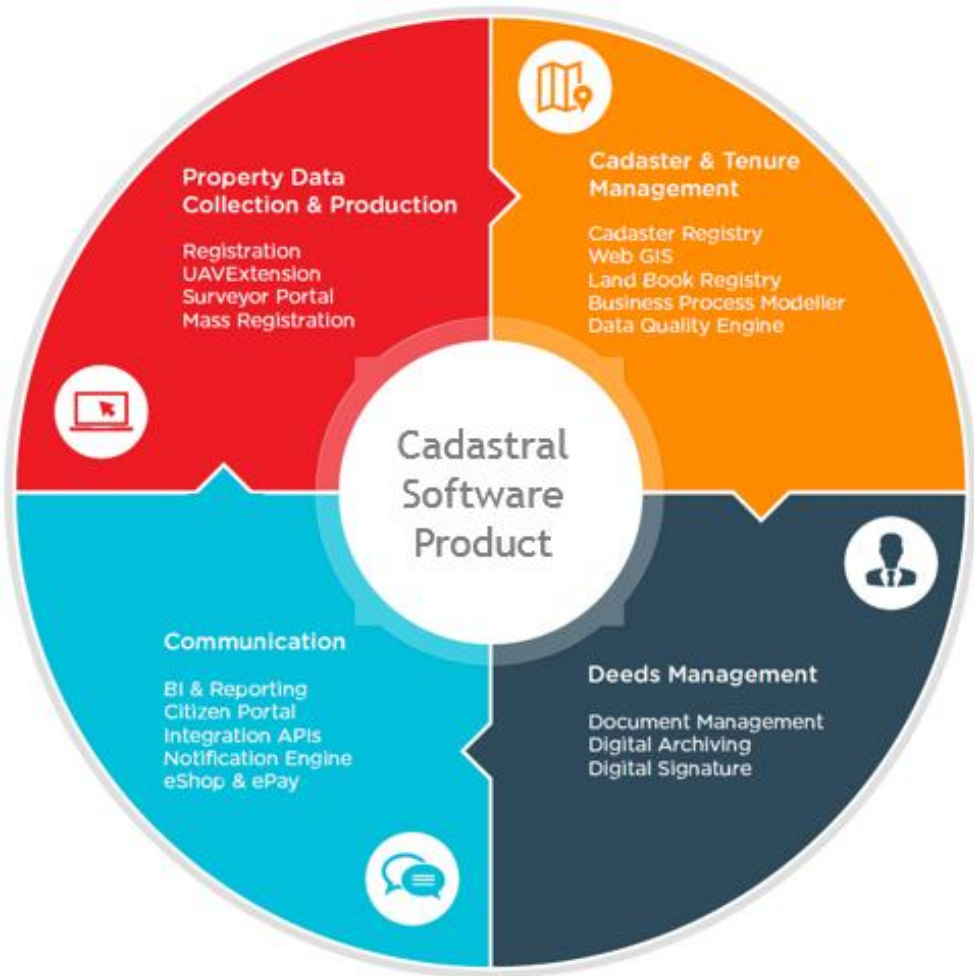

Figure 16 Cadastral Software Product Ecosystem.

Investing in an integrated IT system for a large scale mass registration process could be the first step into decisively increasing the chances of success for such a project. Of course, legal support needs to be harmonized 
with such a strategy and stakeholders trained before the start of such a project. We argue that when such improvements are applied to large scale registration, the total cost of ownership of the IT system could be amortized in less than half of the mass registration duration with a clear impact on the economy and public service quality of the registered geography.

\section{LAND ADMINISTRATION IMPACT ON THE GOVERNMENTAL ECOSYSTEM}

Land administration is about the way people relate to land, probably the most important resource that has modeled the human kind development over its history. Its origins are related to the cadastral and land registration, but its focus has expanded over time to new functions: land use, land value and land development as more specialized polices and strategies are needed to address new and rapidly evolving challenges of developing countries: poverty alleviation, economic development, environmental sustainability, and management of rapidly growing cities and developed ones: emergency management, environmental protection, economic decision making. ${ }^{5}$

Land administration systems are the tools that governments use to manage land-related information in the benefit of the social, economic and environmental development of their countries. They are based on land information infrastructures that are currently benefiting from the technology boom.

The authorities' policies related to land tenure, value, use and development are more efficiently calibrated as they are supported by operative cadastral and land registry (land registration) systems. It is said that "the cadastral system of a country reveals its level of progress, both economically and socially". 6

\section{A. Land Valuation and Taxation}

Land valuation is about developing an opinion related to the value of the land. It is based on characteristics like: location, socioeconomics, government regulations, desirability for residents as a place to live, vicinity to schools, parks and recreational facilities, roadway accessibility, and

\footnotetext{
${ }^{5}$ Stig Enemark, Key Demands for Sustainable Land Administration, InTERNATIONAL FEDERATION OF SURVEYORS (2012), https://www.fig.net/resources/articles_about_fig/coordinates/2012_10_coordinates_enemark.pdf. ${ }^{6}$ Carmen Grecea, Georgiana Rusu, Cosmin Constantin Musat \& Ana Maria Moscovici, CHALLENGES IN IMPLEMENTING THE SYSTEMATIC LAND REGISTRATION IN ROMANIA (Romania: University of Timisoara 2013), http://www.wseas.us/elibrary/conferences/2013/Antalya/GENG/GENG-12.pdf.
} 
distance to retail establishments. ${ }^{7}$

A fair, transparent land valuation framework enables governments and local administrations to efficiently support the development of the real estate markets, to set up land value capture tools such as development fees, land auctions and property taxation based on market valuation in order to generate public revenue to finance investments in land development projects $^{8}$.

The land valuation process is getting more complex as people can easier access and process more diverse and reliable information about its characteristics as a response to the evolution of their needs.

Land valuation provides the necessary input data for the property taxation that represents one of the most reliable generators of Internal Generated Revenue (IGR) since land and buildings are: easily identified, can be seized for nonpayment and represent a repository for accumulated wealth.

These three administrative functions (registration, valuation and taxation) are highly interdependent as incomplete list of properties, delayed or absence of properties updates, inexact property data, difficulties to properly identify owners, conflicts between alleged owners generate property valuation issues that impact the taxation process.

These issues can be addressed by computerization and integration of the systems which manage these public administration functions that would ensure the modified data is updated across all systems when a relevant event occurs, a single-point and real-time access to better information for all stakeholders (citizen, companies and public authorities).
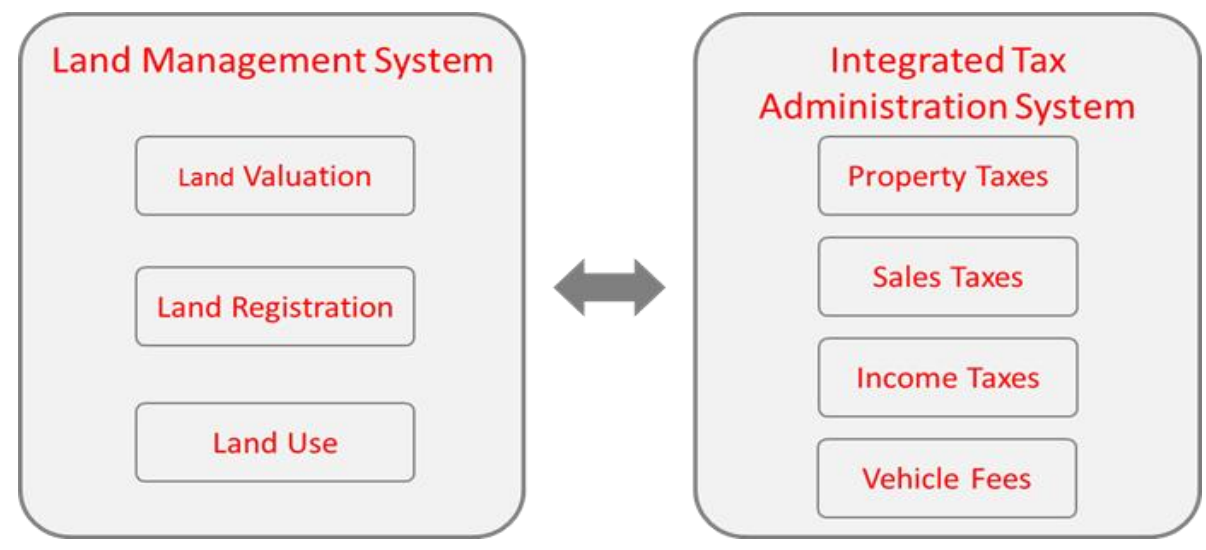

\footnotetext{
${ }^{7}$ www.businessdictionary.com/definition/land-value.html.

${ }^{8}$ WORld BANK Group, MONGOLIA-LAND ADMINISTRATION AND MANAGEMENT IN UlaANBaATAR (Washington DC 2015), http://documents.worldbank.org/curated/en/834131468045555488/MongoliaLand-administration-and-management-in-Ulaanbaatar.
} 
This kind of solution may provide extensive benefits for involved parties:

Land Management:

- Owners are attributed a unique identifier by Tax Administration that facilitates tracking of transactions;

- Transactions can be blocked when issues arise with the owner tax accounts (e.x. selling transactions can be stopped if the taxpayer is under legal action to recover debts by tax administration).

Tax Administration:

- Properties are properly identified and defined through Cadastre;

- Owners are correctly identified based on the Land Registry;

- Transactions are known real-time and taxed accordingly.

Tax Payers:

- A single point of contact can be offered for public services through a portal (Citizen Portal):

- Filing of Tax return;

- Review and payment of existing liabilities;

- Access to cadastral map and land registry;

- Registration of complaints related to property registration and taxes.

\section{B. Emergency Management}

Land administration is highly interconnected with emergency and disaster management at all its functions level:

- Land tenure: provides the information about the land that is affected by a natural or technological disaster or it is the location of an event that requires urgent intervention of the public authorities, its owner and other parties that have "tenure relationships" in relation with the land; this is used to rapidly assess the situation based on land and owner attributes, to contact the owner and other parties in order to limit the potential impact and to efficiently manage the rescue and recovery activities.

- Land valuation: mainly provides the necessary data to correctly evaluate the post-disaster situation in order to protect the vulnerable citizen from the unfair treatment of the assurance companies, to efficiently calibrate the public authorities recovery policies etc;

- Land use: provides valuable information in mitigation and preparedness for intervention activities.

Governments, local authorities and private companies are raising their interest in relation with emergency and disaster management due to the increase of urbanization and industrialization which are generating more and 
new environmental threats.

A performing emergency management system relies on a land management system that can offer real-time, accurate information about the diverse attributes of immovable properties (parcels, buildings and building units) in a spatial context.

This information can be used in:

- search and rescue missions;

- hazard areas mapping;

- evacuation management;

- hazardous materials management.

In conclusion, governmental institutions should manage the implementation of the IT systems in a unique framework which follows an integrated view. The value of the data managed by one institution increases as it is efficiently shared with other individual or institutional consumers that enable all of them to provide or receive a better public service. 